Sharif University of Technology
Scientia Iranica
Transactions A: Civil Engineering
IRAN I I IA
www.scientiairanica.com

\title{
Flexural performance of RC beams strengthened by bonded CFRP laminates under monotonic and cyclic loads
}

\author{
R. Saeidi Moein ${ }^{\mathrm{a}}$, A.A. Tasnimi ${ }^{\mathrm{b}, *}$ and M. Soltani Mohammadi ${ }^{\mathrm{a}}$ \\ a. Department of Earthquake Engineering, Faculty of Civil and Environmental Engineering, Tarbiat Modares University, Tehran, \\ P.O. Box 14155-143, Iran. \\ b. Department of Structural Engineering, Faculty of Civil and Environmental Engineering, Tarbiat Modares University, Tehran, \\ P.O. Box 14155-143, Iran.
}

Received 10 June 2014; received in revised form 24 February 2015; accepted 20 June 2015

\author{
KEYWORDS \\ Strengthened beam; \\ Flexural \\ strengthening; \\ CFRP laminate; \\ Cyclic loading; \\ Debonding failure.
}

\begin{abstract}
RC beams, strengthened by external bonded FRP reinforcement, often fail by one of several possible debonding modes. Although many experimental studies have been performed to assess the flexural behavior and failure modes of FRP-strengthened RC beams under monotonic loads, the flexural performance of these elements under cyclic loads have rarely been examined. The present paper illustrates the results of an experimental study aimed at better understanding of the structural behavior and debonding failure mechanisms of FRP-strengthened RC beams under monotonic and cyclic loads. This experimental research program is made of flexural tests carried out on eight RC beam specimens with dimensions of $150 \mathrm{~mm}$ width, $200 \mathrm{~mm}$ height, and $1800 \mathrm{~mm}$ length, externally strengthened with CFRP laminates and tested under monotonic and cyclic loadings. Three specimens were considered as control specimens. The remaining five specimens were strengthened in flexure by CFRP laminates. This program investigated the structural behavior and debonding failure trends in the FRP-strengthened beams. Results of this investigation are presented in the form of load-deflection curves and FRP strain profiles.
\end{abstract}

(C) 2016 Sharif University of Technology. All rights reserved.

\section{Introduction}

Strengthening Reinforced Concrete (RC) elements using externally bonded Fiber Reinforced Polymer (FRP) composites is one of the most prominent techniques for repair and rehabilitation of existing structures. Depending on the design objectives, bonding FRP laminates and sheets to the external surface of structural members may lead to several improvements in the structural performances, such as the load carrying capacity, stiffness, durability, and serviceability. Most applications of these materials are related to shear

*. Corresponding author. Tel.: +98 2182883385 ;

Fax: +982182884914

E-mail address: tasnimi@modares.ac.ir (A.A. Tasnimi) and flexural reinforcement of beams and confinement of columns and joints. RC elements generally fail by either the crushing of compressive concrete and/or the yielding of the internal steel reinforcement. Although CFRPs have high strength, they are very brittle; when loaded in tension, FRP exhibits a linear stress-strain behavior up to failure without exhibiting a yield plateau or any indication of an impending failure [1]. High strength of FRP is generally not achieved, particularly when it is used externally for the flexural strengthening of RC beams, because the FRPstrengthened members often fail due to a mechanism that is known as debonding.

Debonding can lead to premature failure of the FRP-strengthened members. These failures, such as Intermediate Crack (IC) debonding of FRP, plate end 
interfacial debonding of FRP, and cover separation, can significantly limit capacity enhancement and prevent the full ultimate flexural capacity of the retrofitted beams from being attained [1]. The debonding failure occurs due to initiation and propagation of debonding. This failure mechanism in FRP-strengthened beams depends on the bond behavior at the concrete-FRP interface and generally starts in regions of high stress concentration at the interface. These regions include the ends of FRP reinforcement and those around the flexural or flexural-shear cracks. Location of failure along the beam and thickness of detached concrete cover depend on several parameters such as cracking pattern, internal steel reinforcement percentage, presence of steel stirrups, loading scheme, and interaction between shear and normal bond stresses along the interfaces $[2,3]$. It was found that the use of anchorage techniques, such as U-shaped and L-shaped jackets and steel bolts, could be very useful to avoid or delay the plate end interfacial debonding and cover separation failure and to achieve relevant increase in strength and ductility, but IC debonding of FRP still occurred. The mechanism of IC debonding may be summarized as follows: When a major flexural or flexural-shear crack is formed in the concrete, the tensile stresses released by the cracked concrete are transferred to the FRP reinforcement. As a result, high local interfacial stresses between the FRP and the concrete are induced near the crack. As the applied loading increases further, the tensile stresses in the FRP and hence the interfacial stresses between the FRP and the concrete near the crack also increase. When these stresses reach critical values, debonding starts at the crack and then propagates towards one of the FRP ends [4-5]. Consequently, due to the premature and brittle nature of debonding failures, proper understanding of these failures is needed to insure the safety and reliability of FRP-strengthened members. Although many experimental studies have been performed to assess the flexural behavior of $\mathrm{RC}$ elements externally strengthened with FRP laminates and sheets under monotonic loads [1,2,6-12], the flex- ural behavior of these elements under cyclic loading has rarely been examined. Moreover, the experimental tests carried out under cyclic loads have generally focused on studying fatigue phenomena; thus, they are characterized by a high number of cycles mainly within the elastic range [13-16]. On the contrary, if a low number of cycles occur in the post-elastic field, the seismic response of structure is involved and the inelastic performances of strengthened elements could be investigated [17].

This paper presents an experimental study aimed at better understanding of the structural behavior and failure mechanisms of RC beams strengthened in flexure using external CFRP laminates. Monotonic and quasi-static cyclic loading histories were applied increasingly according to a four-point test scheme until failure occurred in the specimens. Moreover, the plate end anchoring was applied by CFRP sheet wrapping to provide bond anchorage for the flexural CFRP laminates. The main variables in this study are the FRP reinforcement ratio and the presence or absence of the plate end anchoring system.

\section{The experimental program}

\subsection{Specimen details}

The experimental program is made of flexural tests carried out on eight RC beam specimens at the structural engineering laboratory of Tarbiat Modares University (TMU). All specimens were $150 \mathrm{~mm}$ in width, $200 \mathrm{~mm}$ in depth, and $1800 \mathrm{~mm}$ in length. All beams were designed to attain their ultimate flexural strength prior to shear failure following ACI 318 [18] recommendations. Figure 1 illustrates the geometric dimensions and reinforcing details for all specimens. The clear concrete cover to the flexural bars for all beams was set to $25 \mathrm{~mm}$.

All beams were nominated with three to four characters following one or two digits. The first two characters CB represent the Control Beam and SB abbreviates the Strengthened Beam. The third characters "M" or "C" are used to specify either
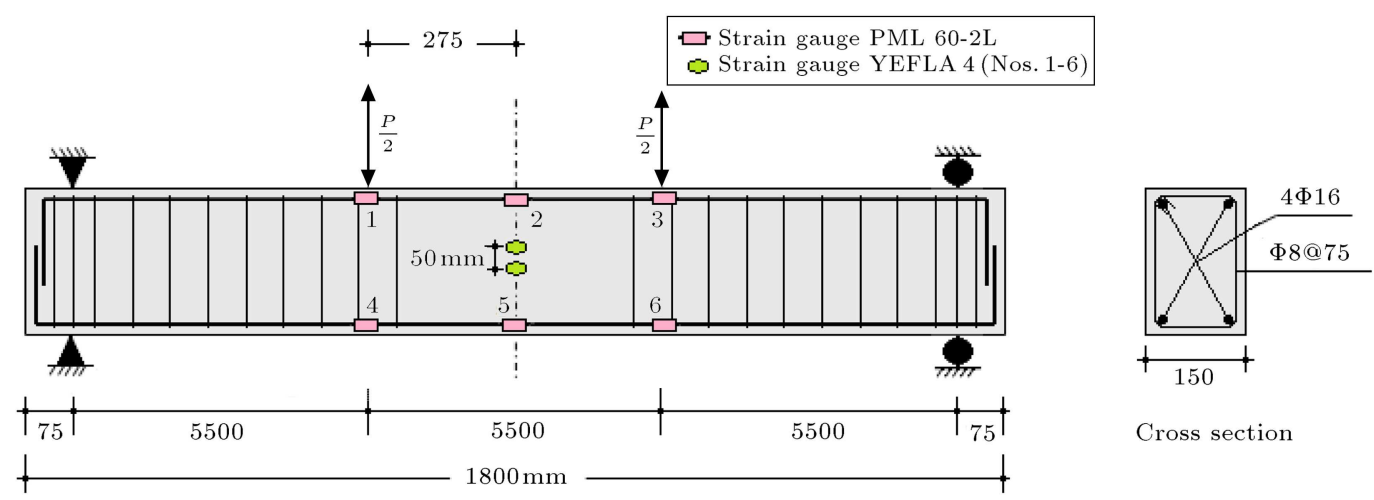

Figure 1. Geometric dimensions and reinforcements, all specimens. 
monotonic or cyclic loadings, respectively. The fourth character "A" indicates the plate end anchorage by CFRP sheet wrapping, and the last two digit numbers specify the width of CFRP laminate bonded on the beam soffit and on the top of the beam. Three of the eight beam specimens were control beams with no FRP strengthening and the remaining five beams had FRP strengthening. Control beams CBM1, CBM2, and $\mathrm{CBC}$ were tested under monotonic, monotonic, and cyclic loadings, respectively. The Strengthened Beams (SB-group) were strengthened in flexure only using externally bonded unidirectional CFRP laminates with various FRP reinforcement ratios. All strengthened beams had one ply of CFRP laminate applied to the beam soffit and one ply of CFRP laminate applied to the top of the beam. Of the five strengthened beams, two beams (SBM50 and SBMA50) were tested monotonically and the remaining three beams (SBCA50, SBCA75 and SBCA100) were tested cyclically.

In the strengthened specimens, all other parameters were kept constant, except the FRP reinforcement ratio and the end anchoring of the FRP laminates which were varied for the failure behavior, debonding mechanisms, and load capacity of beams in various levels of strengthening to be observed. The strengthening configurations and the related parameters are provided in Figure 2 and Table 1, respectively.

\subsection{Material properties}

A normal strength concrete mix-design carried out according to ACI 211.1 [19] using type-1 Portland cement. The mixing proportions of 1.0:1.5:2.1 (cement, coarse, and fine aggregates) with $0.47 \mathrm{w} / \mathrm{c}$ ratio and maximum aggregate size of $12.5 \mathrm{~mm}$ were used for all specimens. Cast specimens were demolded after 24 hours and cured for 28 days using wet blankets covered with plastic sheeting. Table 2 summarizes the properties of concrete used.

Two different batches of steel bars of $16 \mathrm{~mm}$ in diameter were used in the test beams for longitudinal

Table 2. Concrete properties.

\begin{tabular}{cccc}
\hline \multirow{2}{*}{ Specimens } & $\begin{array}{c}\text { Compressive } \\
\text { strength } \\
\boldsymbol{f}_{\boldsymbol{c}}^{\prime}(\mathbf{M P a})\end{array}$ & $\begin{array}{c}\text { Elastic } \\
\text { modulus }\end{array}$ & $\begin{array}{c}\text { Concrete strain } \\
\text { corresponding } \\
\text { to } \boldsymbol{f}_{c}^{\prime} \varepsilon_{o}\left({ }^{*} \mathbf{1 0}^{-\mathbf{3}}\right)\end{array}$ \\
\hline CBM1 & 30.2 & 19.5 & 2.62 \\
CBM2 & 38.7 & 21.4 & 2.80 \\
CBC & 40.6 & 21.9 & 2.85 \\
SBM50 & 32.7 & 20.1 & 2.68 \\
SBMA50 & 40.7 & 21.9 & 2.85 \\
SBCA50 & 39.6 & 21.7 & 2.83 \\
SBCA75 & 41.9 & 22.1 & 2.88 \\
SBCA100 & 33.3 & 20.2 & 2.69 \\
\hline
\end{tabular}
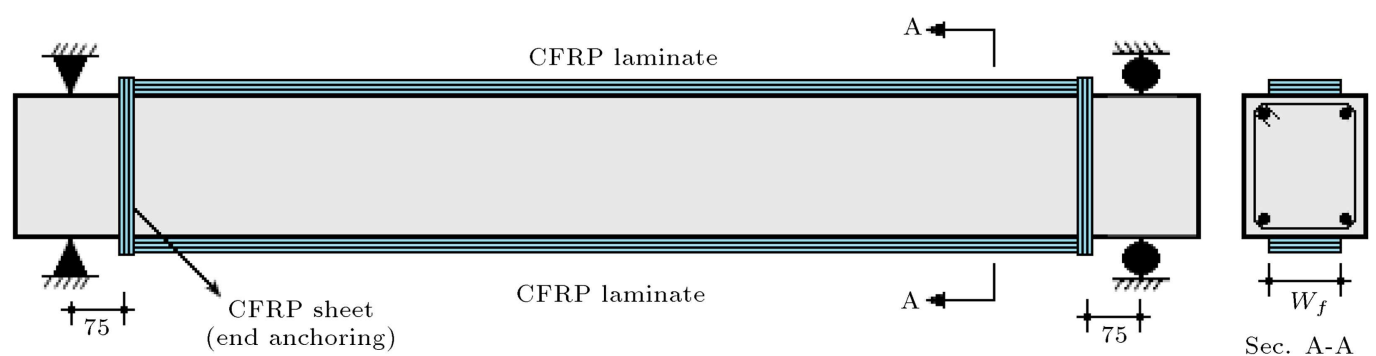

Figure 2. Strengthening configurations of specimens.

Table 1. Strengthening parameters for specimens.

\begin{tabular}{|c|c|c|c|c|c|c|}
\hline \multirow[t]{2}{*}{ Type } & \multirow[t]{2}{*}{ Label } & \multirow{2}{*}{$\begin{array}{l}\text { Loading } \\
\text { history }\end{array}$} & \multicolumn{3}{|c|}{$\begin{array}{c}\text { Strengthening with CFRP } \\
\text { laminate }\end{array}$} & \multirow[t]{2}{*}{ Anchorage } \\
\hline & & & $L_{f}(\mathbf{m m})$ & $w_{f}(\mathbf{m m})$ & $t_{f}(\mathrm{~mm})$ & \\
\hline \multirow{3}{*}{ CB specimens } & CBM1 & Monotonic & - & - & - & - \\
\hline & CBM2 & Monotonic & - & - & - & - \\
\hline & $\mathrm{CBC}$ & Cyclic & - & - & - & - \\
\hline \multirow{4}{*}{ SB specimens } & SBM50 & Monotonic & 1550 & 50 & 1.2 & No \\
\hline & SBMA50 & Monotonic & 1550 & 50 & 1.2 & EA \\
\hline & SBCA 50 & Cyclic & 1550 & 50 & 1.2 & EA \\
\hline & SBCA 75 & Cyclic & 1550 & 100 & 1.2 & EA \\
\hline
\end{tabular}

$\mathrm{CB}=$ Control Beam; $\mathrm{SB}=$ Strengthened Beam; $\mathrm{EA}=$ End Anchorage by CFRP sheet wrapping. 
Table 3. Properties of other materials.

\begin{tabular}{|c|c|c|c|c|c|}
\hline Material & $\begin{array}{c}\text { Yield } \\
\text { strength } \\
f_{y}(\mathrm{MPa})\end{array}$ & $\begin{array}{c}\text { Tensile } \\
\text { strength } \\
f_{t}(\mathrm{MPa})\end{array}$ & $\begin{array}{c}\text { Shear } \\
\text { strength } \\
f_{s}(\mathrm{MPa})\end{array}$ & $\begin{array}{c}\text { Elastic } \\
\text { modulus } \\
E(\mathrm{GPa})\end{array}$ & Application of materials \\
\hline Steel stirrups- $\Phi 8$ & 400 & - & - & 200 & Stirrups placed in all beams \\
\hline $\begin{array}{c}\text { Steel bars- } \Phi 16 \\
\text { Type-1 (1st batch) }\end{array}$ & 400 & - & - & 200 & $\begin{array}{l}\text { Rebar placed in beams } \\
\text { CBM1, SBM50, SBCA100 }\end{array}$ \\
\hline $\begin{array}{c}\text { Steel bars- } \Phi 16 \\
\text { Type-2 (2nd batch) }\end{array}$ & 600 & - & - & 200 & $\begin{array}{c}\text { Rebar placed in beams } \\
\text { CBM2, SBMA50, CBC, SBCA50, SBCA75 }\end{array}$ \\
\hline $\begin{array}{l}\text { CFRP laminate } \\
(\text { Kor-CLS0512) }\end{array}$ & - & 3,420 & - & 171.6 & Flexural strengthening of SB specimens \\
\hline $\begin{array}{l}\text { Epoxy adhesive } \\
\text { (Kor-CPA10) }\end{array}$ & - & 49.5 & 25 & 4.5 & \\
\hline $\begin{array}{c}\text { CFRP sheet } \\
\text { (Kor-CFW300) }\end{array}$ & - & 694.5 & - & 62.1 & End anchorage of CFRP laminates \\
\hline $\begin{array}{c}\text { Resin } \\
(\text { Kor-PNRN) }\end{array}$ & - & 49.8 & - & 3.2 & \\
\hline
\end{tabular}

reinforcement, as the first batch ended at halfway the experimental program. As a result, the first batch of steel bars with the yield strength of $400 \mathrm{MPa}$ was used for longitudinal reinforcement in the beams CBM1, SBM50, and SBCA100, while the second batch of steel bars with the yield strength of $600 \mathrm{MPa}$ was used for longitudinal reinforcement in the beams CBM2, CBC, SBMA50, SBCA50, and SBCA75. Steel stirrups of $8 \mathrm{~mm}$ in diameter, with the yield strength of $400 \mathrm{MPa}$, were used for shear reinforcement in all the test beams. Table 3 provides the properties of steel reinforcement, CFRP laminate, CFRP sheet, epoxy adhesive, and resin used.

\subsection{Specimens preparation}

In order to ensure proper application of FRP materials, the concrete surface was prepared according to the instructions provided by the manufacturer [20]. They included removing the cement paste, grinding the top and bottom faces of the specimens, rounding the edges, and cleaning the specimen by compressed air. The CFRP laminate was thoroughly degreased with acetone and the well-mixed epoxy adhesive was applied to the CFRP laminate and the concrete surface. Finally, the CFRP laminates were glued to the beam. An adhesive thickness of $3 \mathrm{~mm}$ was ensured by means of proper spacers. The laminates were positioned on the top and bottom faces of the specimens and at the center of the beam width. The CFRP-strengthened beams were left for sufficient curing of epoxy adhesive for about one week.

\subsection{Test setup, instrumentation, and loading procedure}

To discuss the pure flexural performance of specimens, all beams were tested in four-point bending as it gives constant maximum moment and zero shear in the section between the loads. The loading was applied as displacement-controlled monotonic or quasi-static cyclic loading history by a reversible two-point loading system located at $275 \mathrm{~mm}$ on either side of the midspan. Monotonic loading was upward with a constant rate of $0.1 \mathrm{~mm} / \mathrm{sec}$ until the beam failed. During cyclic loading, the first cycle of load was upward, and the beams were loaded at a constant rate of $0.1 \mathrm{~mm} / \mathrm{sec}$ and unloaded at $0.5 \mathrm{~mm} / \mathrm{sec}$, according to the loading protocol, as shown in Figure 3. Quasi-static cyclic load-

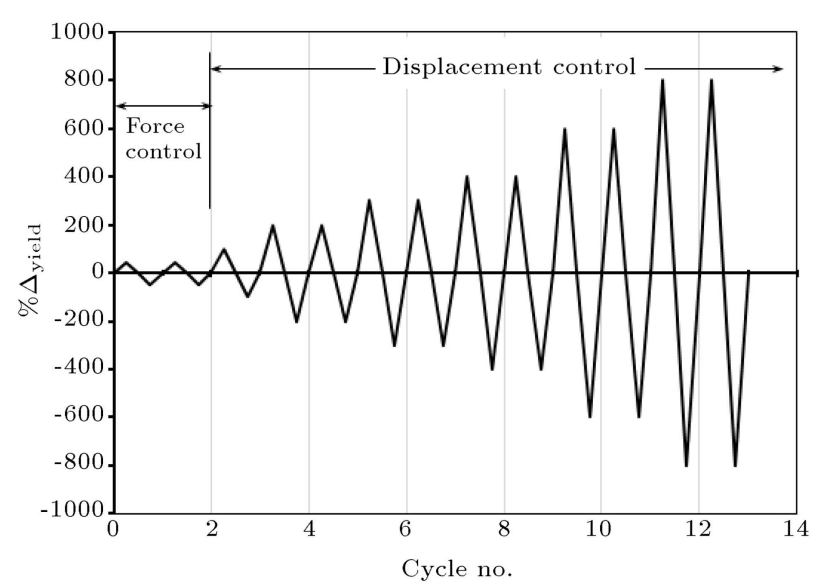

Figure 3. Cyclic loading protocol [21]. 
ing history consisted of two phases. The first phase was force-control and the second phase was displacementcontrol. The first phase of loading is comprised of two cycles imposing a force corresponding to $50 \%$ of the theoretical strength $\left(V_{i}\right)$ of the test specimen. At early stages of the second phase of loading, one fully reversed cycle with equal amplitude of $100 \%$ of the yield displacement was applied. This phase was followed by several subsequent parts, each containing two fully reversed cycles of equal amplitude, corresponding to $200 \%, 300 \%, 400 \%, 600 \%$, and $800 \%$ of the yield displacement. Meanwhile, the yield displacement was determined by extrapolating displacement of the test specimen at $75 \% V_{i}$, which was measured during the test $\left(\Delta_{y}=1.33 \Delta_{0.75 V_{i}}\right)$. All specimens were loaded using a hydraulic jack of $600 \mathrm{kN}$ capacity and maximum stroke of $\pm 100 \mathrm{~mm}$. Load cells were used to record applied loads. Figure 4 shows the schematic testing setup.

All beams were instrumented with six strain gauges of type YEFLA-5 to measure steel strains and two strain gauges of type PML60-2L for concrete strains. The Steel Strain Gauges (SSGs) were installed on the steel bars, and three layers of coating were applied over them for protection during casting of the beams. The Concrete Strain Gauges (CSGs) were installed in two points located at $25 \mathrm{~mm}$ on either side of the middle height of the beam section at mid-span. The locations of steel and concrete strain gauges are shown in Figure 1. The FRP Strain Gauges (FSGs) of type BFLA-5-5 were glued on the top and bottom of CFRP laminates, according to the typical distribution drawn in Figure 5, to measure the strain in FRP. Table 4 shows the number and locations of FSGs glued on each

Table 4. Number of FRP strain gauges glued on SB.

\begin{tabular}{ccc}
\hline Beams & \# of gauges & No. of gauges \\
\hline SBM50 & 14 & $1-14$ \\
SBMA50 & 8 & $2-8,14$ \\
SBCA50 & 11 & $2-8,11-14$ \\
SBCA 75 & 8 & $2-5,11-14$ \\
SBCA100 & 8 & $2-5,11-14$ \\
\hline
\end{tabular}

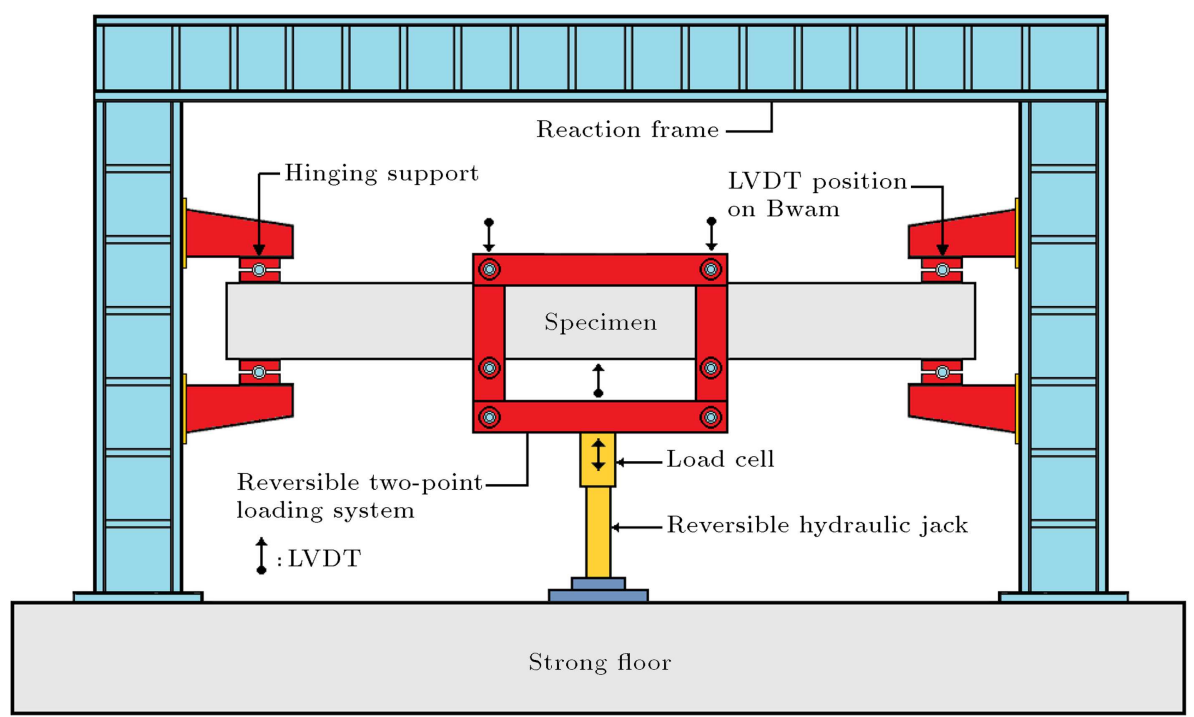

Figure 4. Schematic testing setup.

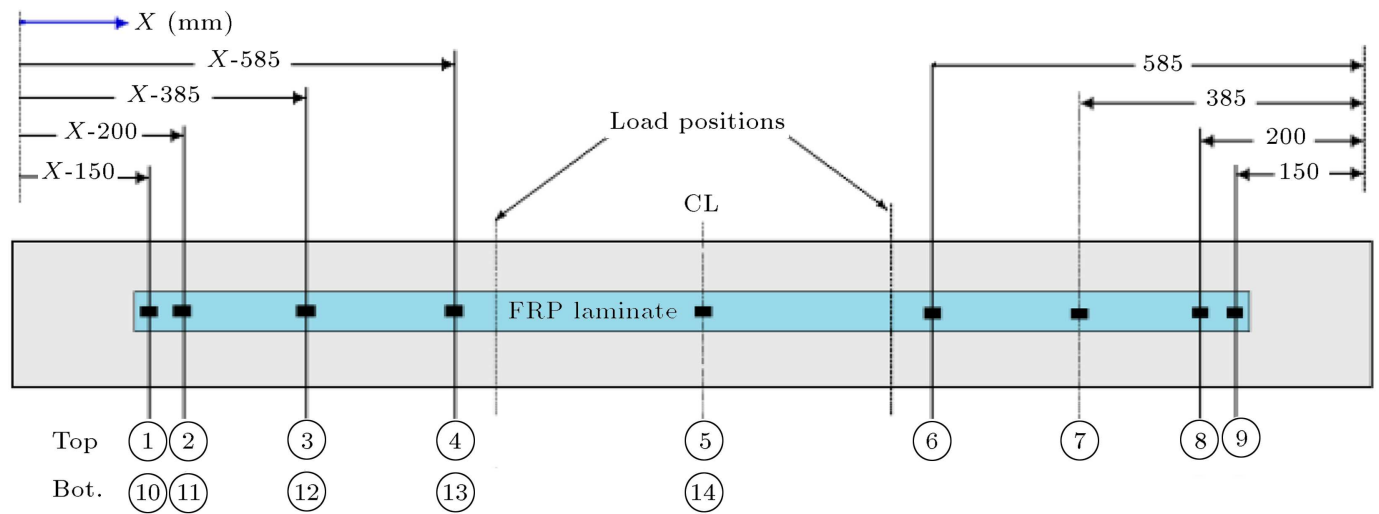

Figure 5. Position of FRP strain gauges along the top and bottom CFRP laminates. 
strengthened beam. The installation of strain gauges on the steel bars and the FRP laminates was carried out according to the manufacturer's instruction [22]. Three Linearly Variable Differential Transducers (LVDTs) were positioned at the mid-span and the load points to measure the deflection during each test. The output data including applied load, deflections, and strains were recorded during the test by a computer data logger system.

\section{Test results and discussions}

The main results obtained from all tested beams, including observed failure modes, load-deflection curves, energy dissipation capacity of beams, and FRP strain profiles are presented in this section.

\subsection{Control beams (not strengthened)}

Figure 6(a) shows the monotonic load-deflection curves for control beams CBM1 and CBM2. The load carrying capacity of beam CBM1 is $114 \mathrm{kN}$, while that of the beam CBM2 is $135 \mathrm{kN}$. The difference in load capacities of monotonic control beams CBM1 and CBM2 can be attributed to the difference in the type of flexural rebars and properties of the concrete used (see Tables 2

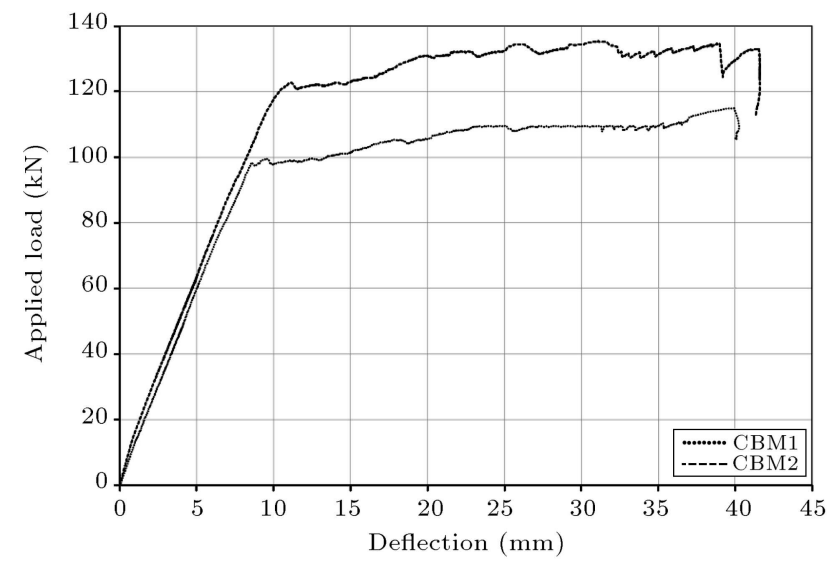

(a) Monotonic control beams CBM1 and CBM2

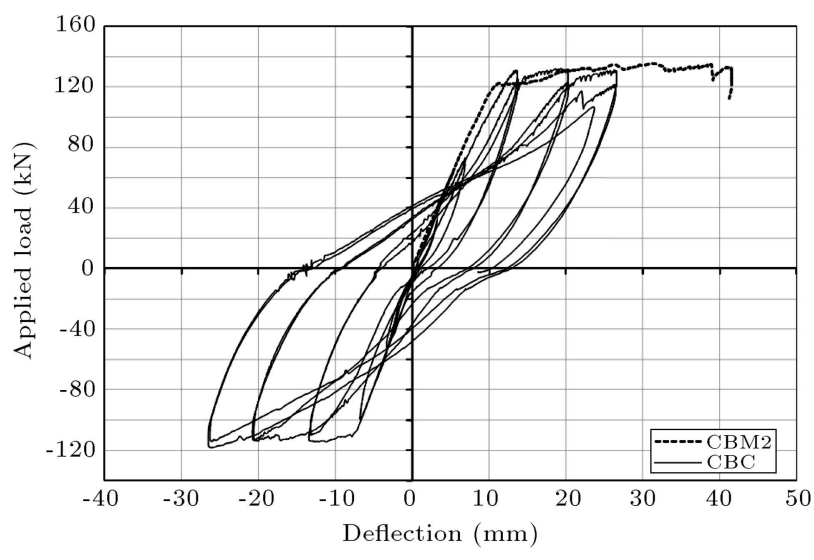

(b) Cyclic control beam $\mathrm{CBC}$ in comparison with CBM2

Figure 6. Load-deflection curve of control beams.

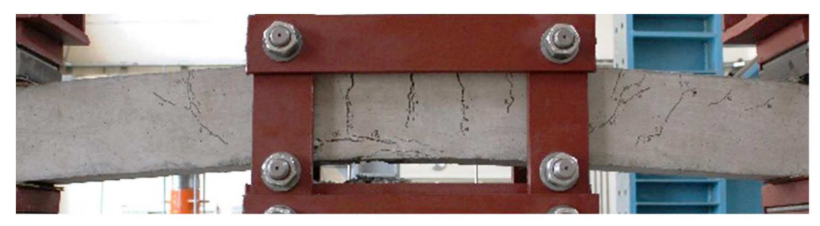

(a) Beam CBM2

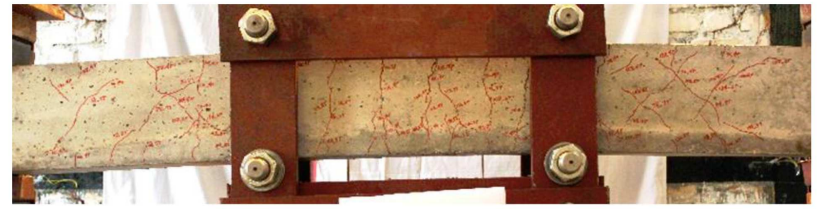

(b) Beam CBC

Figure 7. Cracking pattern and failure mode of control beams CBM2 and CBC.

and 3). The load-deflection curves of CBC and CBM2 specimens show that the same behavior, but with a slight difference in terms of load resistance and ductility, is observed (Figure 6(b)).

The control beams failed by typical steel yielding followed by concrete crushing. Control beams showed wide flexural cracks at mid-span that extended to the compression area. The cracking pattern and failure state of these control beam specimens are shown in Figure 7 .

\subsection{Strengthened beams}

The main objective of the tests in this group is to investigate the flexural behavior of CFRP-strengthened beams with various CFRP reinforcement ratios and different end anchorage conditions under monotonic and cyclic loadings.

\subsubsection{Beams under monotonic loading (SBM50 and SBMA50)}

Load-deflection response and failure modes.

Figure 8 shows the measured load-deflection responses of the beams strengthened with CFRP laminates and tested under monotonic loading. As stated previously, SBM50 and SBMA50 specimens are the strengthened beams corresponding to the control beams CBM1 and CBM2, respectively. Therefore, behavior of SBM50 and SBMA50 was compared with that of their relevant control beams CBM1 and CBM2, respectively. As shown in Figure 8, the load carrying capacities of beams SBMA50 and SBM50 increased in comparison with their relevant control beams (CBM2 and CBM1, respectively) until the debonding failure occurred. After debonding failure, beam SBMA50 showed a behavior similar to its relevant control beam (CBM2), and beam SBM50 behaved as a beam with low strength as compared to its relevant control beam (CBM1).

A close observation of Figure 8 shows that while the load carrying capacity of beam SBMA50 increased $12 \%$ higher than that of the control beam CBM2 (Figure $8(\mathrm{~b})$ ), the load carrying capacity of beam 
SBM50 increased about $8 \%$ higher than that of the control beam CBM1 (Figure 8(a)). The less increase in the load carrying capacity of beam SBM50 is due to the premature failure of this specimen through end debonding of tensile CFRP laminate.

The cracking patterns with failure modes obtained for the beams strengthened with CFRP laminates and tested under monotonic loading are shown in Figure 9. As can be seen from Figure 9(a), the plate end debonding failure mode of beam SBM50 occurred at the right end of tensile laminate (top laminate), fol-

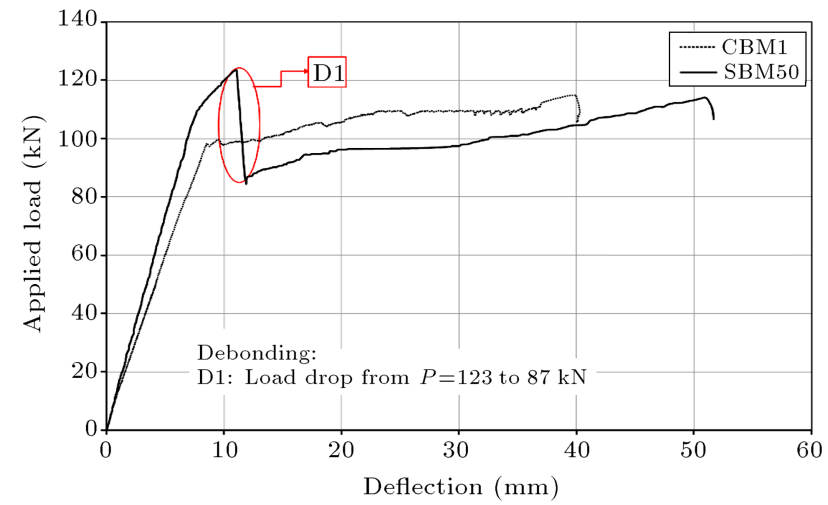

(a) Beam SBM50 in comparison with its relevant control beam CBM

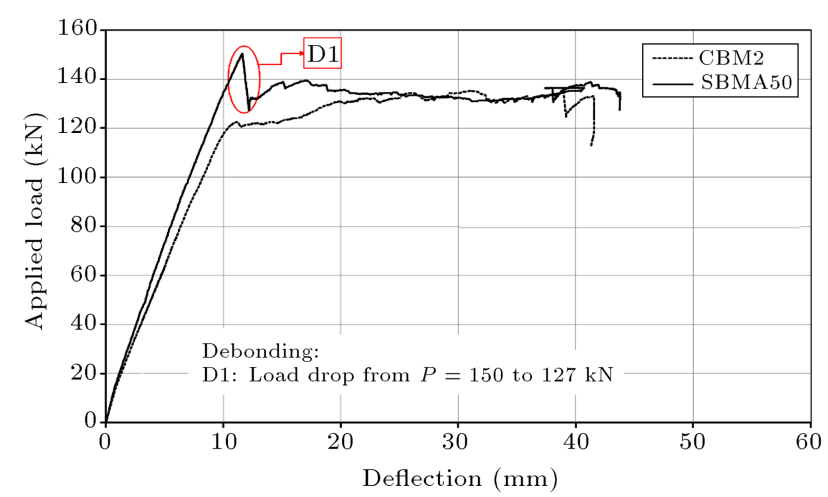

(b) Beam SBMA50 in comparison with its relevant control beam CBM2

Figure 8. Monotonic load-deflection curves.

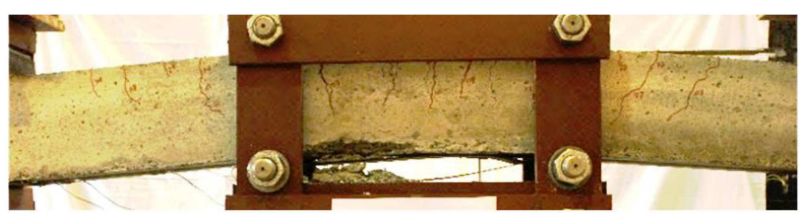

(a) Beam SBM50

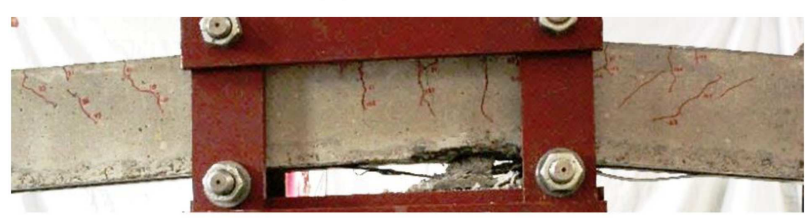

(b) Beam SBMA50

Figure 9. Cracking pattern and failure mode of beams SBM50 and SBMA50. lowed by complete debonding of tensile CFRP laminate and buckling of compressive CFRP laminate. Finally, this beam failed because of the crushing of compressive concrete (flexural failure mode). The debonding failure mode of beam SBMA50 was interfacial debonding of tensile laminate (top laminate) induced by flexuralshear cracks formed in the right shear span of the beam, followed by buckling of compressive CFRP laminate, and finally, by crushing of compressive concrete (Figure $9(\mathrm{~b}))$.

\section{FRP strain profiles.}

The strain profiles of the top CFRP laminates for beams SBM50 and SBMA50 are shown in Figures 10 and 11 , respectively. In these figures, the $x$-axis shows the location of FRP strain gauges (FSGs) along the top CFRP laminate from the Left End of Beam (LEB), and the $y$-axis provides the strain distribution at increasing load levels.

These figures provide a more illustrative distribution of FRP strains and the initiation and propagation of debonding in the CFRP-strengthened beams under monotonic loading. As can be seen from Figures 10 and 11 , the strain profile along the CFRP laminate follows almost a similar pattern, where all strains gradually increase due to load increase, until the load exceeds 123 and $150 \mathrm{kN}$ for beams SBM50 and SBMA50, respectively. For the beam SBM50, after this load level $(123 \mathrm{kN})$, a sharp decrease of FRP strain at the right end of tensile laminate is observed, which results in the end debonding of tensile CFRP laminate.

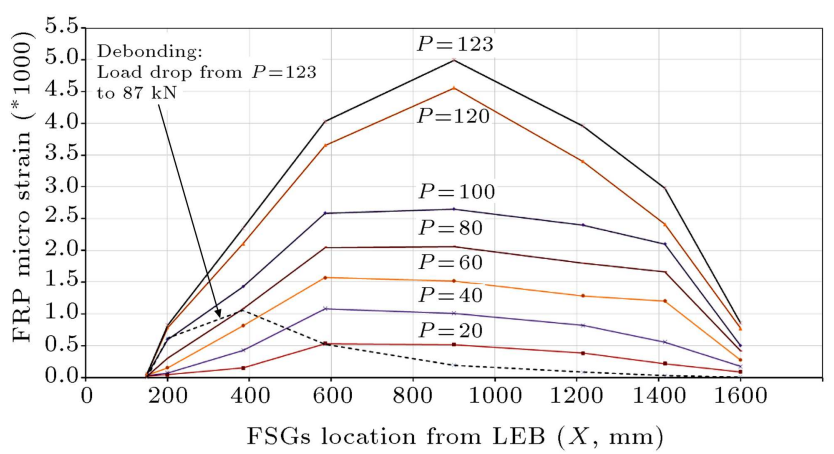

Figure 10. FRP strain profile for beam SBM50.

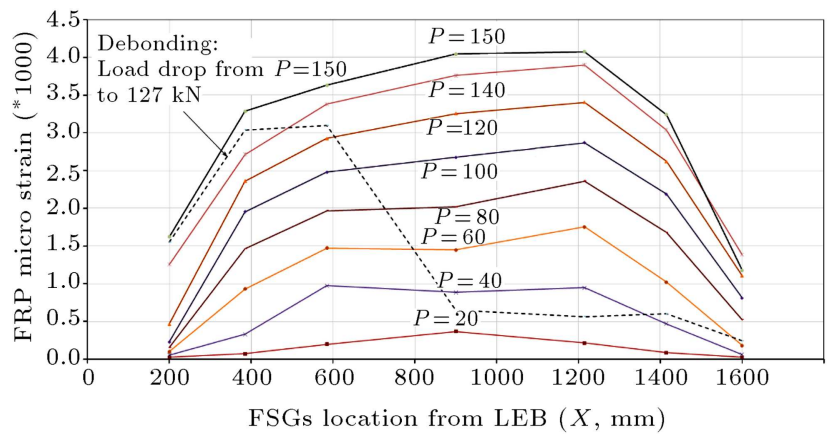

Figure 11. FRP strain profile for beam SBMA50. 
By slight increase of load level, the debonding propagates towards the center of the beam, and causes the complete debonding of tensile CFRP laminate and the buckling of compressive CFRP laminate. For the beam SBMA50, the decrease of FRP strain at the right shear span of the beam is observed in Figure 11, which occurs due to initiation and propagation of the interfacial debonding of top laminate induced by flexural-shear cracks formed in the shear span of the beam. Due to extensive shear cracking close to the loading points, the strain concentration of laminate at these points is observed in Figures 10 and 11, where the FRP strains at points close to the load position (FSG-4 at location $X=585 \mathrm{~mm}$ in Figure 10 and FSG-6 at location $X=1215 \mathrm{~mm}$ in Figure 11) exceed the FRP strains at mid-span (FSG-5).

\subsubsection{Beams under cyclic loading (SBCA50, $S B C A 75$, and $S B C A 100$ )}

Load-deflection response and failure modes The load-deflection curves of two identical CFRPstrengthened beams tested under monotonic (SBMA $50)$ and cyclic (SBCA50) loadings are shown in Figure 12. As shown in this figure, the behavior and characteristics of two beams are nearly identical, as the backbone of load-deflection curve of specimen SBMA50 appears as the envelope curve for the load-deflection curve of specimen SBCA50. The load-deflection curves obtained for the remaining two CFRP-strengthened beams tested under cyclic loading (SBCA75 and SBCA100) are shown in Figures 13 and 14, respectively.

It should be noted that the beam CBC is the control beam corresponding to all cyclic strengthened beams, except SBCA100 that has different material properties (see Tables 2 and 3). As a result, the load capacity of the beams SBCA50 and SBCA75 was compared with that of the control beam $\mathrm{CBC}$, while the load capacity of SBCA100 was compared with that of its relevant control beam, CBM1. The increases in load capacities of SBCA50 and SBCA75, compared with

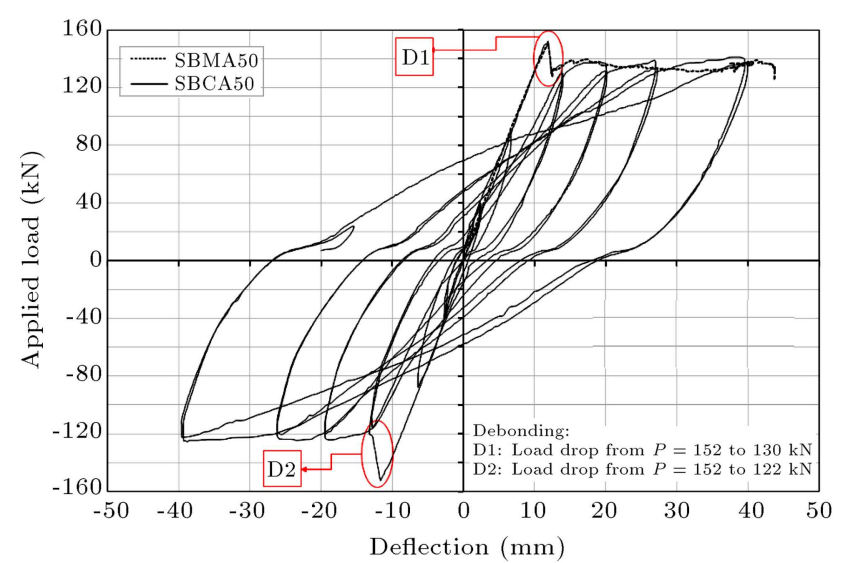

Figure 12. Cyclic load-deflection curve for SBCA50 in comparison with SBMA50.

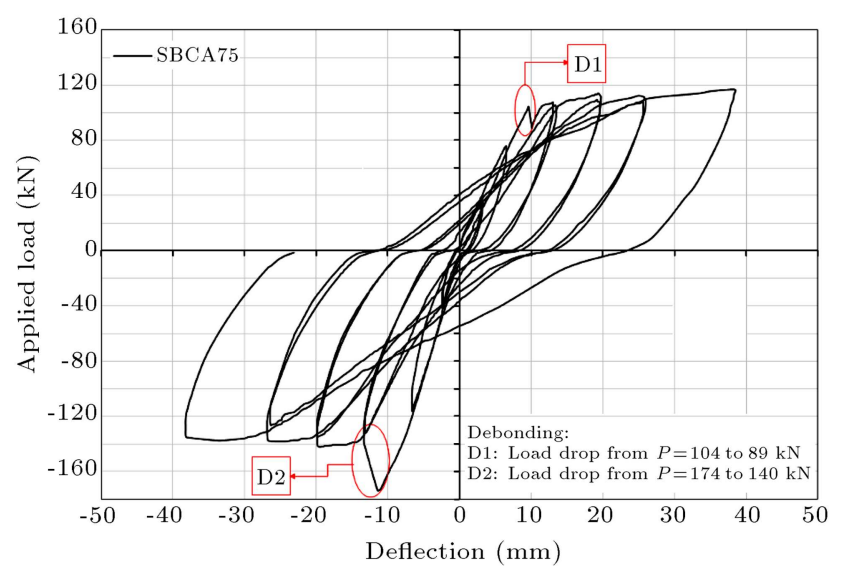

Figure 13. Cyclic load-deflection curve for beam SBCA75.

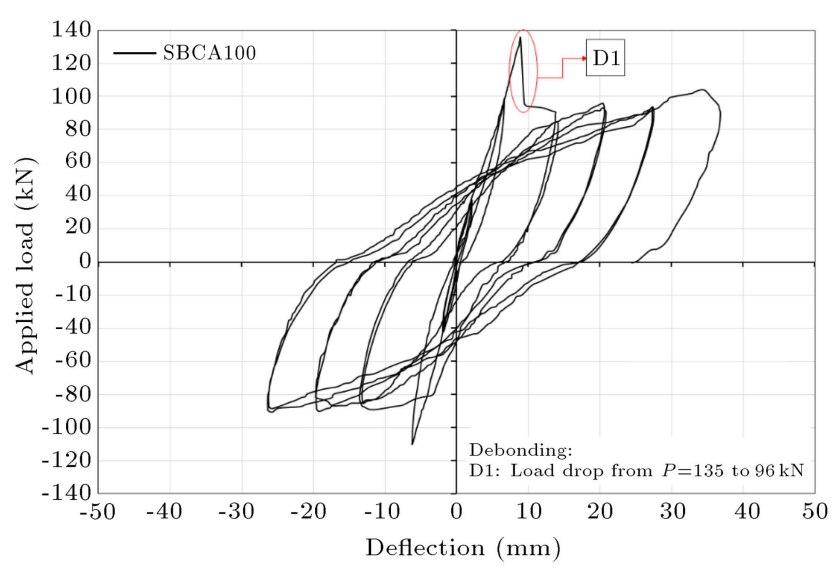

Figure 14. Cyclic load-deflection curve for beam SBCA100.

that of the beam CBC, were $15 \%$ and $31 \%$, respectively. The load capacity of SBCA100 was $18 \%$ higher than that of the beam CBM1.

It is remarkable to emphasize the close observation of Figures 13 and 14 that over-increasing the FRP reinforcement ratio can be detrimental to the structural performance of the strengthened beams. The increase in load carrying capacity of beam SBCA100, having high FRP reinforcement ratio as compared to the beams SBCA50 and SBCA75, is lower than those of the beams SBCA50 and SBCA75. This shows the importance of design against debonding, especially when high FRP reinforcement ratios are used.

The cracking pattern and failure state of cyclic strengthened specimens are shown in Figure 15. The failure mode of beams SBCA50, SBCA75, and SBCA100 was the interfacial debonding of CFRP laminates followed by complete debonding of top and bottom CFRP laminates (Figure 15). For all cyclic strengthened specimens, the debonding of top and bottom laminates occurred in the 4th upward and downward cycles of load, respectively, which are described in the following: 
Table 5. Energy dissipation capacity of cyclic specimens (kN.mm).

\begin{tabular}{|c|c|c|c|c|c|c|c|c|c|}
\hline \multirow{4}{*}{ Specimens } & \multicolumn{8}{|c|}{ Mean value of energy dissipation capacity per cycle } & \multirow{4}{*}{$\begin{array}{c}\text { Total energy } \\
\text { dissipation } \\
\text { (up to } 9 \text { th } \\
\text { cycle) }\end{array}$} \\
\hline & $\begin{array}{l}\text { 2nd } \\
\text { cycle }\end{array}$ & $\begin{array}{c}\text { 3rd } \\
\text { cycle }\end{array}$ & $\begin{array}{c}4 \text { th } \\
\text { cycle }\end{array}$ & $\begin{array}{c}5 \text { th } \\
\text { cycle }\end{array}$ & $\begin{array}{c}6 t h \\
\text { cycle }\end{array}$ & $\begin{array}{c}7 \mathrm{th} \\
\text { cycle }\end{array}$ & $\begin{array}{c}8 \text { th } \\
\text { cycle }\end{array}$ & $\begin{array}{c}9 \text { th } \\
\text { cycle }\end{array}$ & \\
\hline & Force control & \multicolumn{7}{|c|}{ Displacement control } & \\
\hline & $P=40 \mathrm{kN}$ & $\Delta=6.65 \mathrm{~mm}$ & \multicolumn{2}{|c|}{$\Delta=13.30 \mathrm{~mm}$} & $\Delta=19.95 \mathrm{~mm}$ & \multicolumn{3}{|c|}{$\Delta=26.60 \mathrm{~mm}$} & \\
\hline $\mathrm{CBC}$ & 44 & 189 & 1199 & 904 & 2464 & \multicolumn{3}{|c|}{3773} & 14853 \\
\hline SBCA50 & $62(1.41)^{*}$ & $295(1.56)$ & $1464(1.22)$ & $799(0.88)$ & $2173(0.88)$ & \multicolumn{3}{|c|}{$3637(0.96)$} & $14301(0.96)$ \\
\hline $\mathrm{SBCA} 75$ & $68(1.55)$ & $312(1.65)$ & $1494(1.25)$ & $758(0.84)$ & $2120(0.86)$ & \multicolumn{3}{|c|}{$3571(0.94)$} & $14103(0.95)$ \\
\hline SBCA100\# & 75 & 325 & 1838 & 1408 & 2629 & \multicolumn{3}{|c|}{3806} & 16617 \\
\hline
\end{tabular}

* The values listed in the parentheses are the ratios of energy dissipation capacity of strengthened specimens to that of the control beam CBC.

\# The ratio of energy dissipation capacity of beam SBCA100 to that of CBC has not been calculated, because the beam CBC is not the relevant control beam of SBCA100 (see Tables 2 and 3).

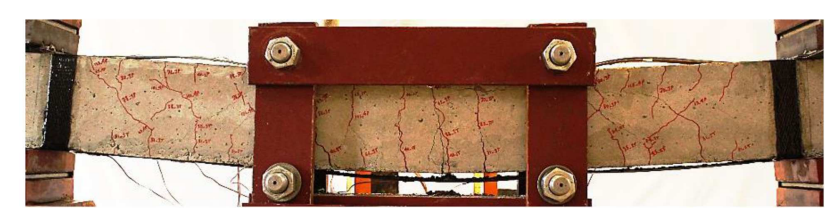

(a) Beam SBCA50

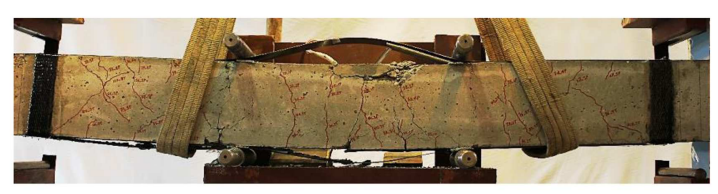

(b) Beam SBCA75

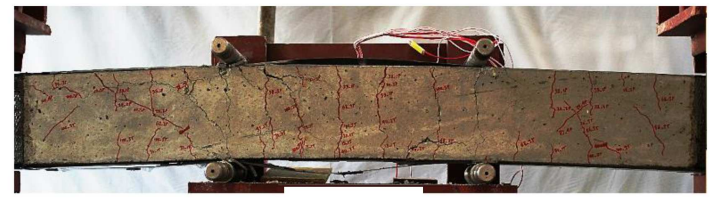

(c) Beam SBCA100

Figure 15. Cracking pattern and failure mode of beams SBCA50, SBCA75, and SBCA100.

(a) Beam SBCA50: The debonding of top laminate started from the location of FSG-4 and propagated towards the left end of beam and the mid-span (FSG-5), while that of bottom laminate started at the mid-span (FSG-14) and propagated towards both ends of the beam;

(b) Beam SBCA75: The debonding of top laminate started at the mid-span (FSG-5) and propagated towards the right end of beam, while that of the bottom laminate started from the location of FSG13 and propagated towards the left end of beam and the mid-span;

(c) Beam SBCA100: The debonding of both top and bottom laminates started from the points close to the left load position (FSG-4 and FSG-13, respectively) and propagated towards the left end of beam and the mid-span.

It should be noted that the location of FSG-4 and FSG-13 is close to the load position in the left shear span of beam, while that of FSG-5 and FSG-14 is at the mid-span (see Figure 5).

\section{Energy dissipation capacity.}

An important issue in the context of seismic performance is the comparison of energy dissipation capacity of the strengthened specimens with that of the control ones. In this study, the energy dissipation capacity of each cyclic strengthened beam is evaluated by computing the area enclosed by the cyclic curve, and compared with that of the corresponding control beam (CBC). The calculated energy dissipation capacities for all cyclic strengthened beams and the ratios of energy dissipation of these specimens to that of the corresponding control beam are listed in Table 5 .

As found from Table 5, the energy dissipation capacity (per cycle) of the strengthened beams SBCA50 and SBCA75 are more than that of the control beam CBC by $22-65 \%$ up to the 4 th cycle of load (the first cycle of $\Delta=13.30 \mathrm{~mm}$ ), in which the debonding of CFRP laminates occurs. After that, the energy dissipation capacity (per cycle) of these strengthened beams are less than that of the control beam CBC by 4$16 \%$. It is also clear from Figure 16 that strengthening $\mathrm{RC}$ beams using CFRP laminates leads to increase in the energy dissipation capacity (per cycle) of specimens until the FRP debonding occurs, and just after that, the energy dissipation capacity decreases, significantly. The energy dissipation capacity (per cycle) of strengthened specimens increases with the FRP reinforcement ratio until the FRP debonding occurs, and afterward, its value remains almost constant for various FRP reinforcement ratios.

Figure 17 shows the energy dissipation capacity of cyclic specimens. As seen in this figure, the amount of total energy dissipated by the strengthened beams is slightly lower than that by the corresponding control beam, CBC, with the exception of SBCA100 specimen whose energy dissipation capacity is higher than that of $\mathrm{CBC}$. This is due to the change in the type of flexural 


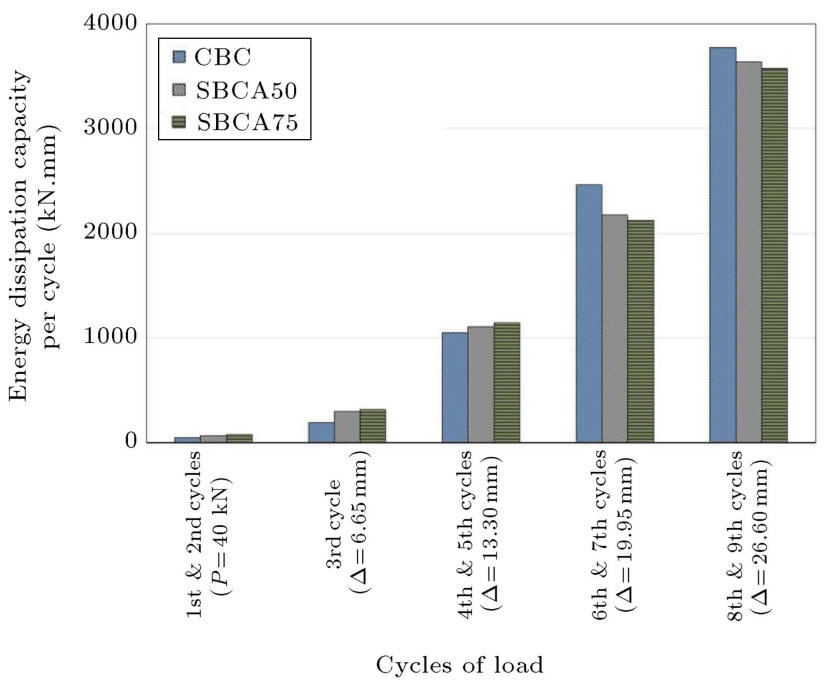

Figure 16. Comparative diagrams of mean energy dissipation capacity of control (CBC) and strengthened (SBCA50 and SBCA75) beams.

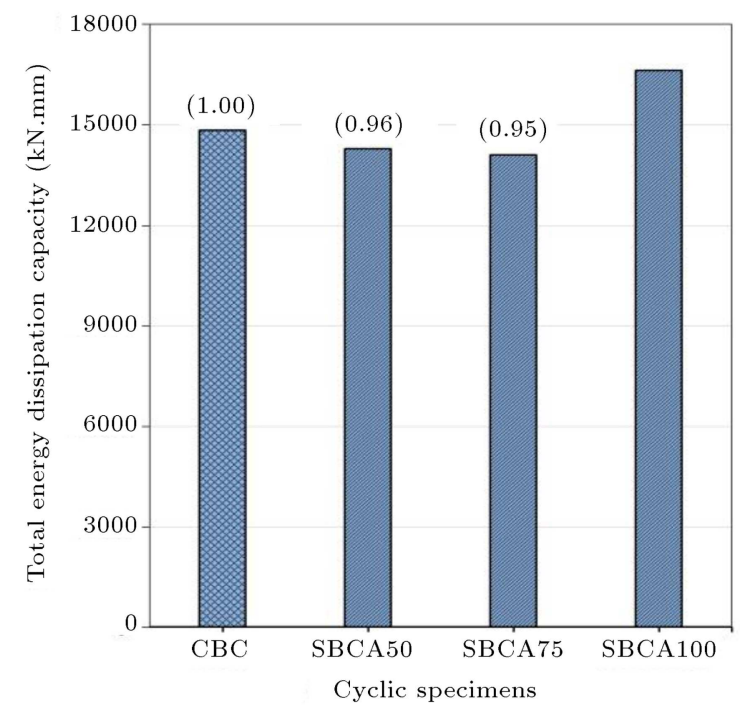

Figure 17. Comparative diagrams of energy dissipation capacity of control and strengthened beams.

rebar and properties of concrete used in SBCA100 (see Tables 2 and 3 ).

\section{FRP strain profiles}

The FRP strain profiles of beams SBCA50, SBCA75, and SBCA100 are shown in Figures 18, 19, and 20, respectively. As already stated, the FRP strain profile shows the location of FRP Strain Gauges (FSGs) along the CFRP laminate from the Left End of Beam (LEB) on the $x$-axis and the strain distribution at increasing load levels on the $y$-axis. In these figures, strain distribution of the top and bottom CFRP laminates for the upward and downward cycles of load is presented in the states (a) and (b), respectively. The figures provide a more illustrative distribution of FRP strains and the initiation and propagation of debonding in the

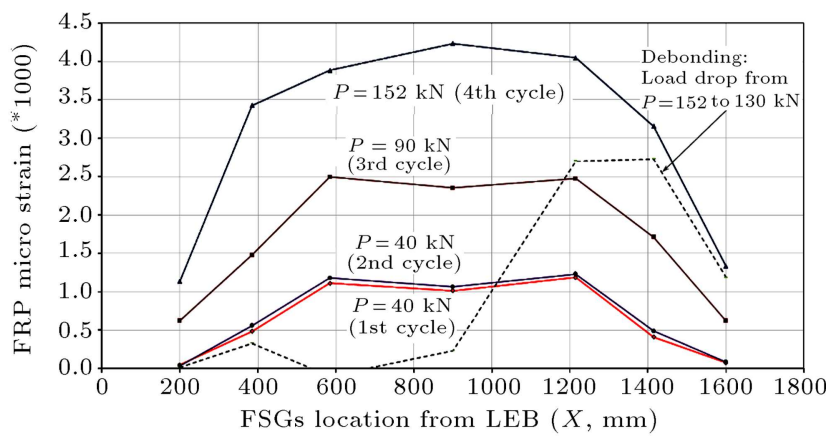

(a) Top CFRP laminate

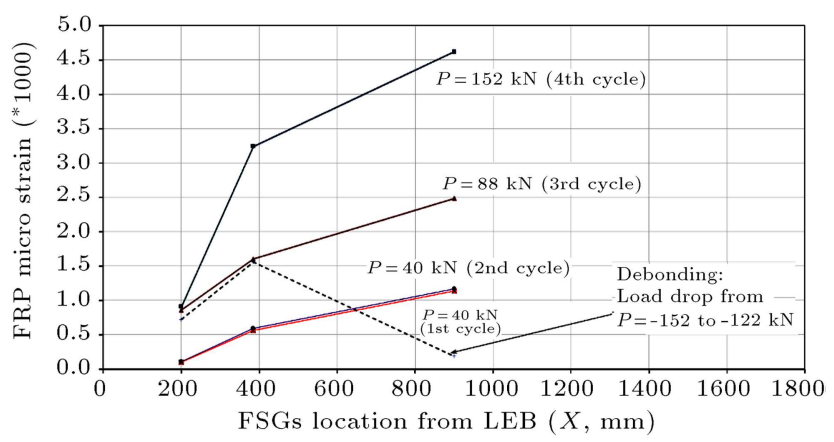

(b) Bot. CFRP laminate

Figure 18. FRP strain profile beam SBCA50.

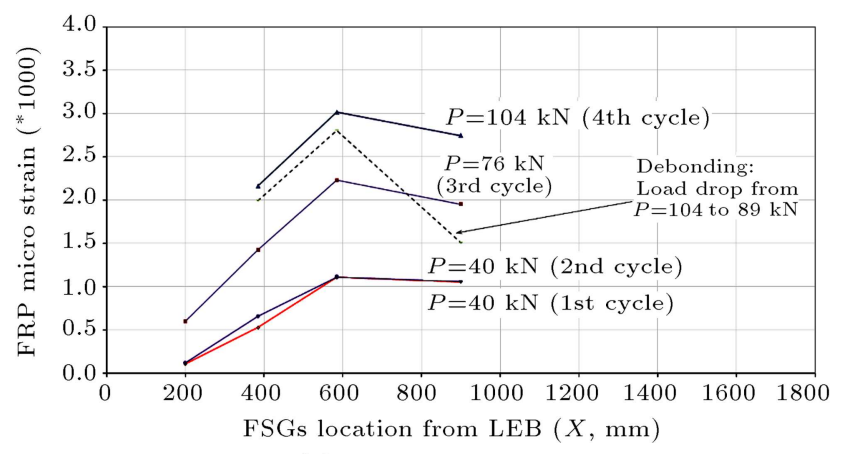

(a) Top CFRP laminate

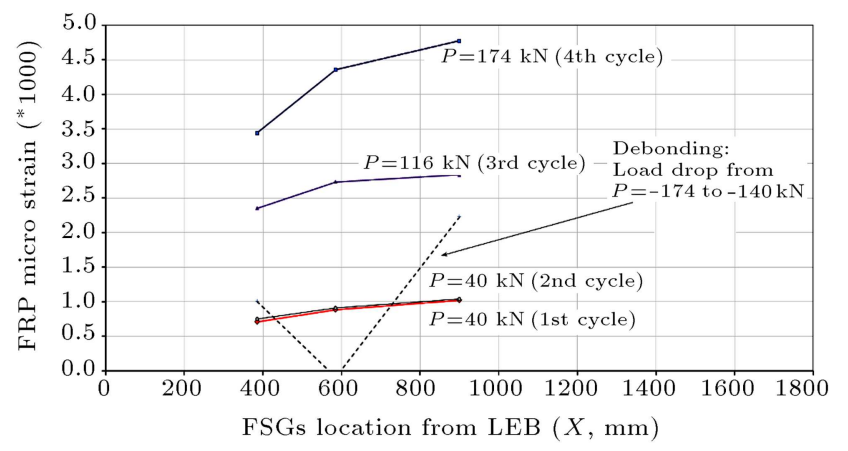

(b) Bot. CFRP laminate

Figure 19. FRP strain profile for beam SBCA75.

beams strengthened with CFRP laminates under cyclic loading.

As shown in these figures, the strain profile along the CFRP laminate follows almost a similar pattern, where all strains gradually increase due to load 


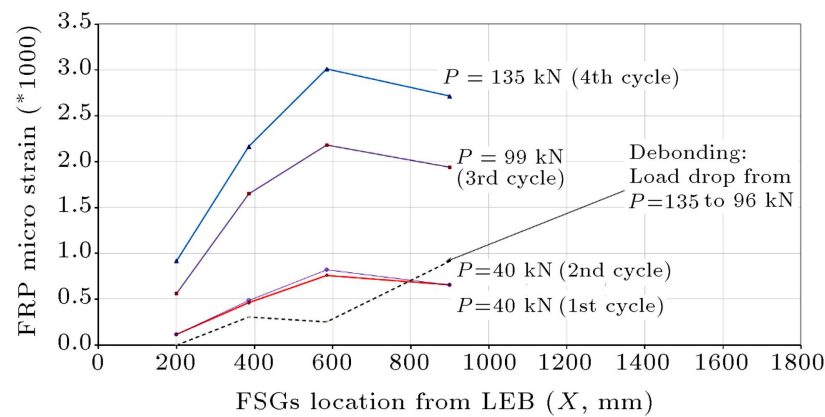

Figure 20. Strain profile of top CFRP laminate for beam SBCA100.

increase, until the load exceeds a special critical value for each beam. After this critical load, decrease of FRP strain in the shear span of the beam (the regions close to the loading points) or in the mid-span is observed, which occurs due to initiation and propagation of the interfacial debonding of CFRP laminate induced by flexural or flexural-shear cracks formed in the midspan or shear span of the beam. Due to extensive shear cracking close to the loading points, the stress concentrations are observed in some of these figures, where the FRP strains in the shear zone exceed the FRP strain at mid-span.

For the beam SBCA50, the load of debonding was $152 \mathrm{kN}$ in the 4 th cycle. The debonding failure of this specimen occurred due to initiation and propagation of the interfacial debonding of top laminate induced by flexural-shear cracks formed in the left shear span of the beam, and the interfacial debonding of bottom laminate induced by flexural cracks formed in the midspan. At the 4th cycle, the debonding of the top and bottom CFRP laminates decreased the load carrying capacity of beam to 130 and $122 \mathrm{kN}$ for upward and downward cycles of load, respectively. As a result, a sharp drop of 22 and $30 \mathrm{kN}$ in the load level occurred in the upward and downward cycles of load, respectively.

For the beam SBCA75, the debonding of the top and bottom CFRP laminates was observed when the load exceeded $104 \mathrm{kN}$ (the 4th upward cycle of load) and $174 \mathrm{kN}$ (the 4th downward cycle of load), respectively. The debonding failure of this specimen occurred due to initiation and propagation of the interfacial debonding of top laminate induced by flexural cracks formed in the mid-span, and the interfacial debonding of bottom laminate induced by flexural-shear cracks formed in the left shear span of the beam.

As shown in the two above figures, at 4th cycle, the debonding of the top and bottom CFRP laminates decreased the load carrying capacity of beam to 89 and $140 \mathrm{kN}$ for upward and downward cycles of load, respectively. As a result, a sharp drop of 15 and $34 \mathrm{kN}$ in the load level occurred in the upward and downward cycles of load, respectively.

For the beam SBCA100, observation of Figure 20 shows that the FRP strain along the top CFRP laminate decreases when load level in the 4th upward cycle exceeds $135 \mathrm{kN}$ (Figure 20). Due to the debonding of top CFRP laminate, a sharp drop in the load level equal to $39 \mathrm{kN}$ is observed.

The debonding failure of this specimen occurred due to initiation and propagation of the interfacial debonding of top CFRP laminate induced by flexuralshear cracks formed in the left shear span of the beam.

\section{Conclusions}

In this article, the effect of variation of FRP reinforcement ratio and plate end anchoring on the behavior and failure mechanisms of RC beams externally strengthened with CFRP laminates were studied, experimentally. Based on the results of tested specimens under monotonic and quasi-static cyclic loadings, the following conclusions are drawn:

1. While the debonding failure mode of the strengthened beam, that had no plate end anchorage (SBM50 specimen), was plate end debonding failure, that of the remaining strengthened specimens with end anchorages was interfacial debonding induced by flexural or flexural-shear cracks formed in the mid-span or in the shear span of the beam, respectively;

2. The strengthened beam that had no plate end anchorage (SBM50), exhibited less increase in the load carrying capacity due to the premature failure through end debonding of tensile CFRP laminate;

3. The load carrying capacities of CFRP-strengthened beams under monotonic loading significantly increased about $12 \%$ (except the beam SBM50 that had no plate end anchorage) in comparison with their relevant control beams, until when the debonding failure occurred. However, due to the debonding failure, the load carrying capacity of specimens decreased as a sharp drop by over $14 \%$;

4. Based on the results of SBM50 and SBMA50 specimens, providing plate end anchorage for the flexural CFRP laminates in CFRP-strengthened beams could result in significant improvement in the behavior and performance of specimens. This improvement was exhibited with $22 \%$ increase in the load carrying capacity and prevention of occurrence of plate end debonding in flexural CFRP laminate;

5. By comparing the results of SBCA50, SBCA75, and SBCA100 with those of their relevant control beams, it can be found that increasing the amount of FRP reinforcement by $50 \%$ results in increase of the load capacity from $15 \%$ to $31 \%$, while overincreasing the FRP reinforcement ratio to $100 \%$ 
results in increase of the load capacity to $18 \%$. This shows the importance of design against debonding, especially when high FRP reinforcement ratios are used;

6. Based on the results of cyclic strengthened specimens, strengthening RC beams using CFRP laminates can lead to increase in the energy dissipation capacity (per cycle) of specimens until the FRP debonding occurs, and just after that, the energy dissipation capacity decreases significantly. For high cycle of loads, it is found that the energy dissipation capacity (per cycle) of the strengthened specimens is almost similar to that of the control specimens;

7. The energy dissipation capacity (per cycle) of strengthened specimens increases with the FRP reinforcement ratio until the FRP debonding occurs, and afterwards, its value remains almost constant for various FRP reinforcement ratios;

8. Finally, regarding the above-mentioned statements, the most important result obtained from this experimental work is that FRP strengthening may not only be ineffective, but may also be detrimental to the structural performance and safety unless properly designed. This is due to the premature and brittle nature of debonding failures.

\section{References}

1. Maghsoudi, A.A. and Akbarzadeh Bengar, H. "Acceptable lower bound of the ductility index and serviceability state of RC continuous beams strengthened with CFRP sheets", Scientia Iranica, Transaction A: Civil Engineering, 18(1), pp. 36-44 (2011).

2. Yao, J. and Teng, J.G. "Plate end debonding in FRP-plated RC beams- I: Experiments", Engineering Structures, 29, pp. 2457-2471 (2007).

3. Seracino, R., Saifulnaz, M.R.R. and Oehlers, D.J. "Generic debonding resistance of EB and NSM plateto-concrete joints", Journal of Composites for Construction, ASCE, 11(1), pp. 62-70 (2007).

4. Teng, J.G., Chen, J.F., Smith, S.T. and Lam, L., FRP Strengthened RC Structures, Wiley, New York, USA (2002).

5. Ceroni, F., Pecce, M., Matthys, S. and Taerwe, L. "Bond tests on concrete elements with CFRP and anchorage systems", Journal of Composites, Part B, 39, pp. 429-441 (2008).

6. Hashemi, H., Maghsoudi, A.A. and Rahgozar, R. "Bending response of HSRC beams strengthened with FRP sheets", Scientia Iranica, Transaction A: Civil Engineering, 16(2), pp. 138-146 (2009).

7. Esfahani, M.R., Kianoush, M.R. and Tajari, A.R. "Flexural behavior of reinforced concrete beams strengthened by CFRP sheets", Engineering Structures, 29, pp. 2428-2444 (2007).
8. Aram, M.R., Czaderski, C. and Motavalli, M. "Debonding failure modes of flexural FRPstrengthened RC beams", Journal of Composites, Part B, 39, pp. 826-841 (2008).

9. Kotynia, R., Abdel Baky, H.M., Neale, K.W. and Ebead, U.A. "Flexural strengthening of RC beams with externally bonded CFRP systems: Test results and 3D nonlinear FE analysis", Journal of Composites for Construction, ASCE, 12(2), pp. 190-201 (2008).

10. Ceroni, F. and Pecce, M. "Design provisions for crack spacing and width in RC elements externally bonded with FRP", Journal of Composites, Part B, 40(1), pp. 17-28 (2009).

11. Siddiqui, N.A. "Experimental investigation of RC beams strengthened with externally bonded FRP composites", Latin American Journal of Solids and Structures, 6, pp. 343-362 (2009).

12. Taleb Obaidat, Y., Heyden, S., Dahlblom, O., AbuFarsakh, G. and Abdel-Jawad, Y. "Retrofitting of reinforced concrete beams using composite laminates", Construction and Building Materials, 25, pp. 591-597 (2011).

13. Kim, Y.J. and Heffernan, P.J. "Fatigue behavior of externally strengthened concrete beams with fiber reinforced polymers: state of the art", Journal of Composites for Construction, ASCE, 12(3), pp. 246256 (2008).

14. Ferrier, E., Bigaud, D., Clement, J.C. and Hamelin, P. "Fatigue-loading effect on RC beams strengthened with externally bonded FRP", Construction and Building Materials, 25, pp. 539-546 (2011).

15. Aidoo, J., Harries, K.A. and Petrou, M. "Fatigue behavior of carbon fiber reinforced polymer strengthened reinforced concrete", Journal of Composites for Construction, ASCE, 8(6), pp. 501-509 (2004).

16. Heffernan, P.J. and Erki, M.A. "Fatigue behavior of reinforced concrete beams strengthened with carbon fiber reinforcement", Journal of Composites for Construction, ASCE, 8(2), pp. 132-140 (2004).

17. Ceroni, F. "Experimental performances of RC beams strengthened with FRP materials", Construction and Building Materials, 24, pp. 1547-1559 (2010).

18. ACI 318, Building Code Requirements for Reinforced Concrete, American Concrete Institute, ACI 318, Farmington Hills, Michigan, USA (2008).

19. ACI 211, Standard Practice for Selecting Proportion for Normal, Heavy Weight and Mass Concrete, American Concrete Institute, ACI 211.1, Farmington Hills, Michigan, USA (1991).

20. http://www.carbonfrp-korearent.com "Carbon FRP plates and fabrics application process" (2012).

21. Filiatrault, A., Wanitkorkul, A. and Constantinou, M. "Development and appraisal of a numerical cyclic loading protocol for quantifying building system performance", Technical report MCEER-08-0013, pp. 3-4 (2008).

22. http://www.tml.jp/e/index.html "Primary installations" (2012). 


\section{Biographies}

Reza Saeidi Moein is currently $\mathrm{PhD}$ candidate in Earthquake Engineering, Faculty of Civil and Environment Engineering, Tarbiat Modares University (TMU), Tehran, Iran. His field of research includes seismic behavior of RC elements strengthened with FRP composites. He received his MSc degree from International Institute of Seismology and Earthquake Engineering (IIEES), Tehran, Iran, in 2004, and BSc degree in Civil Engineering from Amirkabir University of Technology, Tehran, Iran, in 2001. His research interests include experimental investigations on RC elements, RC retrofitting, and seismic response assessment of reinforced concrete structures.

Abbas Ali Tasnimi is a Full Professor of Structural Engineering, Faculty of Civil and Environment Engineering, Tarbiat Modares University (TMU), Tehran, Iran. He is the member of various scientific committees and sub-committees of Iranian National Building Code and the Permanent Revised Committee of Standard 2800 for seismic design of buildings. His research interests include nonlinear mechanics and constitutive laws of reinforced concrete, seismic nonlinear analysis, mathematical and numerical modeling of reinforced concrete structures, and seismic response assessment and rehabilitation of $\mathrm{RC}$ and masonry structures. He has held many academic positions since 1989. Presently, he is the Head of the Department of Earthquake Engineering, TMU. He was formerly President of the Iranian Earthquake Engineering Association (20042010).

Masoud Soltani Mohammadi is an Associate Professor of Civil Engineering at Tarbiat Modares University. He received his $\mathrm{PhD}$ from the University of Tokyo, Tokyo, Japan. His research interests include nonlinear mechanics and constitutive laws of reinforced concrete, numerical modeling of masonry structures, and seismic response assessment and rehabilitation of structures. 